order. It seems, using a cumulative dose response, that the metered aerosol after nebuliser did not allow maximum potential increase in lung function.

Previous studies comparing metered aerosol with nebuliser have used different dosages. ${ }^{3}$ This has led to argument about whether different responses were related to the dose or the method of administration. In this study, the doses were similar, although the amount reaching the lower airways cannot be clearly predicted. It is likely that only a small fraction, probably less than $20 \%$ of each dose, did reach the lower airways, but slight differences do not seem to be significant. The nebuliser technique used was such that much of the dose was wasted during the expiratory phase of ventilation. The minimal effect of dose on the response in this study of children with mild to moderate asthma agrees with the observation of Reilly et $a l^{4}$ and Ruffin et $a t^{6}$.

Tarala $e t \mathrm{al}^{7}$ showed that repeated puffs of metered dry aerosol would give a similar response to a wet aerosol, although the wet aerosol did produce significantly greater bronchodilatation after six to eight puffs of dry aerosol, supporting the observations in this study.

For most patients the choice between a metered aerosol and nebuliser for administration of sympathomimetic drugs should be based on cost, age, and ability to use a metered aerosol, as there is little difference in the response by either route. For most children with asthma over 4 to 6 years of age, a dry or metered aerosol is adequate. Wet aerosol by nebuliser does seem, however, to be more effective in achieving maximum potential bronchodilatation and is probably the treatment of choice in troublesome chronic asthma as well as during the severe acute episode when inhalation of the metered aerosol dose is difficult.

C $M$ was supported by a travelling fellowship funded by Bochringer-Ingelheim.

\section{References}

1 Anonymous. Management of severe acute asthma [Editorial]. Br Med J 1978;i:873-4.

2 Shenfield GM, Paterson JW. Clinical assessment of bronchodilator drugs delivered by acrosol. Thorax 1973;28:124-8.

${ }^{3}$ Chook-Kang YFJ, Grant IWB. Comparison of two methods of administering bronchodilator acrosol to asthmatic patients. $\mathrm{Br}$ Med J 1975;ii:119-20.

+ Reilly PA, Yahar J, Mindorff C, Kazim F, Levison H. Dose-response characteristics of nebulized fenoterol in asthmatic children. J Pediatr 1983:103:121-6.

5 Polgar G, Promadhat V. Pulmonary function testing in children. Philadelphia: Saunders, 1971.

'Ruffin RW, Montgomergy JM, Newhova MT. Site of beta adrenergic receptors in the respiratory tract: use of fenoterol administered by two methods. Chest 1978:74:256-60.

7 Tarala RA, Madsen BW, Paterson JW. Comparative efficacy of salbutamol by pressurized acrosol and wet nebulizer in acute asthma. Br J Clin Pharmacol 1980;10:393-7.

Correspondence to Professor L I Landau, Department of Child Health, Princess Margaret Hospital for Children, Box D184, GPO. Perth, Western Australia, 6001 Australia.

Received 28 September 1984

\title{
Inspiratory time and tidal volume during intermittent positive pressure ventilation
}

\author{
D FIELD, A D MILNER, AND I E HOPKIN
}

Department of Neonatal Medicine and Surgery, City Hospital, Nottingham

SUMmARY We measured the tidal volume achieved during intermittent positive pressure ventilation using various inspiratory times with a minimum of $0 \cdot 2$ seconds. Results indicate that tidal volume shows no reduction with inspiratory times down to 0.4 seconds. An inspiratory time of 0.3 seconds, however, is likely to reduce tidal volume by $8 \%$, and at $0 \cdot 2$ seconds a $22 \%$ fall may be anticipated.

For the past 10 years most babies with the idiopathic respiratory distress syndrome have been ventilated using square wave ventilation at ventilator rates ranging from 20 to 40 breaths per minute. Willingness to exceed a respiratory rate of 40 seems to be limited by a belief that short inspiratory times do not provide adequate oxygenation. ' During the past year we have found that ventilator rates of up to 100 breaths per minute may produce considerable benefit. ${ }^{2}$ We were, however, concerned that very brief inspiratory times might reduce tidal volume appreciably, which would result in alveolar hypoventilation. We therefore attempted to assess at what inspiratory time a fall in tidal volume was likely to occur. 


\section{Subjects}

The data were collected from 43 babies studied on 52 occasions over an 18 month period: all were suffering from idiopathic respiratory distress syndrome. Their gestational ages ranged from 25 to 34 weeks (mean 29 weeks) and their birthweights from 680 to $2470 \mathrm{~g}$ (mean $1255 \mathrm{~g}$ ).

\section{Method}

Measurements were made of three parameters:

(1) Tidal volume. A Fleisch type 0 pneumotachograph was connected between the baby's endotracheal tube and the patient manifold of the ventilator. A high pressure suction pump (Airshields Diapump) was connected to the distal portion of the pneumotachograph via a 21 gauge needle. The needle limited the flow produced by the pump to 2 litres per minute. Once the ventilator circuit was compensated for this loss, the bias flow produced no effect on the ventilator's performance but produced a zero dead space effect for the pneumotachograph, which enabled readings to be made for periods of up to three hours. The signal derived from the pneumotachograph was electronically integrated to produce a volume signal. Calibration was performed against a syringe.

(2) Inflation pressure. A wide bore needle was inserted into the endotracheal tube at the point where it entered the mouth. This was connected to a SE Laboratories 4.86 pressure transducer. Calibration was performed using a water manometer.

(3) Oesophageal pressure. A $3 \mathrm{~cm}$ oesophageal balloon on a 6 French gauge catheter was passed into the oesophagus of any baby thought fit enough to withstand the manoeuvre. 'This was then connected to a pressure transducer. Calibration was performed as above. Oesophageal signals were merely used to determine whether or not the baby was making respiratory efforts.
The signals were displayed on an oscillograph and could be recorded on a Devices recorder.

All babies were ventilated on Draeger Babylog ventilators (time cycled pressure limited). Each baby was studied over a period of up to three hours. Data were collected over a range of inspiratory times in which peak inspiratory pressure and positive end expiratory pressure were kept constant. Expiratory time always equalled or exceeded inspiratory time, and even at the fastest ventilator rates was never less than 0.2 seconds. Because of clinical constraints, the number of comparable inspiratory times obtained during each study varied from two to seven.

Mean tidal volume on each setting was calculated for at least 20 ventilator inflations. This was performed either by direct measurement from the paper trace or by using computer analysis. ${ }^{3}$ Inflations modified by the babies' own respiratory efforts were rejected.

\section{Results}

Tidal volume measurements were collected on a total of 172 different ventilator settings during 52 study periods. In those studies where an inspiratory time of 0.5 seconds was adopted at some point during the series of ventilator changes, the value for tidal volume obtained was taken to represent $100 \%$. Tidal volumes for other inspiratory times employed during that particular study were then calculated as a percentage of the 0.5 second result. In 18 of the 52 study periods a value for tidal volume with an inspiratory time of 0.5 seconds was not obtained. Whenever possible the next longest inspiratory time to 0.5 seconds was then substituted $(0.4(3), 0.6(5)$, $0 \cdot 7(3), 0 \cdot 8(5))$. The results for inspiratory time as a percentage of tidal volume are shown in the Table. Tidal volume in general was well maintained at $0 \cdot 4$ seconds where only three of the 23 values obtained showed a greater than $10 \%$ reduction in tidal volume compared with the standard value. At $0 \cdot 3$ seconds an overall $8 \%$ reduction in tidal volume was observed and in 14 of the 34 studies the reduction

Table Mean and standard deviations for tidal volumes obtained at varying inspiratory times

\begin{tabular}{|c|c|c|c|c|c|c|c|c|c|}
\hline & \multicolumn{9}{|c|}{ Inspiratory time (secs) } \\
\hline & $0 \cdot 2$ & 0.3 & $0 \cdot 4$ & 0.5 & $0 \cdot 6$ & 0.7 & $0 \cdot 8$ & 0.9 & $1 \cdot 0$ \\
\hline No of values & 13 & 34 & 23 & 34 & 14 & 23 & 12 & 6 & 13 \\
\hline $\begin{array}{l}\text { Tidal volume as \% of standard } \\
\text { Mean } \\
\text { (SD) }\end{array}$ & $\begin{array}{l}78.6 \dagger \\
(18 \cdot 3)\end{array}$ & $\begin{array}{l}90 \cdot 6^{*} \\
(15 \cdot 6)\end{array}$ & $\begin{array}{l}101 \cdot 4 \\
(16 \cdot 2)\end{array}$ & $\begin{array}{l}100^{*}+ \\
-\end{array}$ & $\begin{array}{l}107 \\
(9 \cdot 9)\end{array}$ & $\begin{array}{l}100 \cdot 3 \\
(14)\end{array}$ & $\begin{array}{l}102 \cdot 3 \\
(15 \cdot 7)\end{array}$ & $\begin{array}{l}104 \\
(12 \cdot 2)\end{array}$ & $\begin{array}{l}108 \\
(22 \cdot 3)\end{array}$ \\
\hline
\end{tabular}

${ }^{*} \mathrm{P}<0 \cdot 01$.

$\dagger \mathrm{P}<0 \cdot 001$. 
exceeded $10 \%$. With an inspiratory time of $0 \cdot 2$ seconds, a mean fall of $22 \%$ was seen in tidal volume with a greater than $10 \%$ drop in nine of 13 studies.

\section{Discussion}

The results show that tidal volume is well maintained with inspiratory times down to and including $0 \cdot 4$ seconds. With an inspiratory time of 0.3 seconds, there is a small decrease in tidal volume but reduction of inspiratory time to 0.2 seconds is associated with a $22 \%$ fall in tidal volume. We ensured in the studies presented here that expiratory time was always at least equal to inspiratory time. At the highest ventilator rates, however, the short expiratory time may have contributed to the loss of tidal volume. An inspiratory time of 0.4 seconds or less, used in conjunction with a rapid ventilator rate, will produce a minute volume which is apparently more than satisfactory for the infant's requirement. Dead space, however, remains constant during ven- tilation and any reduction in tidal volume cannot always be compensated for by an increased ventilator rate.

The relation between fast ventilator rates and blood gas status is a complex one and does not depend entirely on tidal volume. ${ }^{2}$ It would seem appropriate to recommend that care be taken when using intermittent positive pressure ventilation with inspiratory times less than $0 \cdot 3$ seconds.

\section{References \\ 1 Reynolds EOR. Effect of alterations in mechanical ventilator settings on pulmonary gas exchange in hyaline membrane disease. Arch Dis Child 1971:46:152-9. \\ ${ }^{2}$ Field D, Milner AD, Hopkin IE. High and conventional rates of positive pressure ventilation. Arch Dis Child 1984;59:1151-4. \\ 3 Stokes CM, Milner AD, Hodges IGC, Henry R, Elphick M. Nebulised therapy in acute severe bronchiolitis of infancy. Arch Dis Child 1983:58:279-83.}

Correspondence to Professor A D Milner, Department of Neonatal Medicine and Surgery, City Hospital, Nottingham NG5 1PB.

Received 4 November 1984

\title{
Reference ranges for serum $\alpha_{1}$ antitrypsin
}

\author{
A MILFORD WARD, P A E WHITE, AND G WILD
}

Supraregional Specific Protein Reference Unit, Royal Hallamishire Hospital, Sheffield

SUMMARY References ranges for serum $\alpha_{1}$ antitrypsin at various ages have been constructed using specific protein calibration material (SPS-01). Median values and 5th-95th centile ranges for $\alpha_{1}$ antitrypsin in cord blood are equivalent to those of the adult. The median concentration falls during the first 6 months of age to rise again to adult values by 12 months. Concentrations in early school age are higher than in normal adults.

The estimation of serum $\alpha_{1}$ antitrypsin is of value in the assessment of liver disease in childhood ${ }^{\prime}$ as well as in chronic obstructive airway disease. ${ }^{2}$ The comparison of results between centres has been hampered to an extent by the lack of correlation between various available standards of calibrants. This problem has not been alleviated to any great degree by the availability of an international refer- ence preparation because of the general reluctance to change from familiar mass concentrations to the more anonymous units. This variability of calibrants was a major factor in the desire to produce a national working calibrant for specific protein assays within UK laboratories. ${ }^{3}$

This report details reference ranges for serum $\alpha_{1}$ antitrypsin for various ages throughout childhood in relation to the specific protein calibration material (SPS-01). Because of the known influence of the PI genetic system on serum concentrations of $\alpha_{1}$ antitrypsin $^{4}$ all samples have been subjected to PI phenotype evaluation.

\section{Materials and methods}

Blood samples were obtained from 590 normal healthy children between the ages of 6 months and 15 years as part of a study of $\mathrm{IgE}$ values in the offspring of asthmatic parents. Consent for vene- 